Methods: Four regional hospitals participated with study period from 1/1/2006 to $30 / 6 / 2016$. IgG4RD patients were classifed into definite, probable and possible IgG4RD according to Japanese Comprehensive Diagnostic Criteria for IgG4RD (3).

Statistical analysis: Association between the individual categorical covariates and the different organ involvement were analyzed by Fisher's exact test.

Results: 108 patients were included. There were 81 male patients and 27 female patients and the male to female ratio is $3: 1$. The mean age of diagnosis was 62.8 year old. 57 patients were diagnosed as definite IgG4RD (53\%), 14 patients as probable IgG4RD (13\%) and 37 patients as possible IgG4RD (34\%). Salivary glands involvement was the commonest, $(M=45.7 \%$ vs $F=33.3 \%)$, followed by pancreas $(M=28.4 \%$ vs $F=18.5 \%)$ and biliary system in male $(M=24.7 \%$ vs $\mathrm{F}=11.1 \%)$ and orbital in female ( $\mathrm{M}=23.5 \%$ vs $\mathrm{F}=18.5 \%) .53 \%$ patients also had multi organ involvement.

104 patients had serum lgG4 level checked and it was raised in 94 patients (90.4\%). 77 patients (74.0\%) had IgG4 level above twice upper limit of normal. IgG4 level was normal in 10 patients. $98 \%$ and $86.3 \%$ patients with multi organ involvement had lgG4 level $>135 \mathrm{mg} / \mathrm{dL}(\mathrm{p}=0.016)$ and $>270 \mathrm{mg} / \mathrm{dL} \quad(\mathrm{p}=0.007)$ respectively. In the hepatobiliary group $(n=36), 30$ patients had blood checked for Ca19.9 level and it was raised in 17 patients (56.7\%), with the highest level $14127 \mathrm{U} / \mathrm{ml}$. 71 histological reports were available. Lymphoplasmacytic infiltration was a consistent features in all specimens $(100 \%)$. Eosinophilic infiltration was seen in 19 specimen $(27 \%)$. Fibrosis was seen in 44 specimens $(63 \%)$. Sialadenitis and dacryoadenitis were associated with dense fibrosis. Obliterative phlebitis was seen in 7 specimens (10\%). IgG4/lgG ratio was reported in 61 specimens. 53 specimens had $\operatorname{lgG} 4 / \operatorname{lgG}$ ratio greater than $40 \%$ per high power field which accounted for $86.9 \%$ of the specimens.

Conclusions: Most patients were male with the peak diagnosis at age 50 to 70. Salivary gland and pancreas were the most common organ involved. Most patients had a raised lgG4 level and most histological specimens showed a raised IgG4/lgG ratio on immunostaining. IgG4 level twice the upper limit of normal was quite specific for the disease and was associated with multi organ involvement

References:

[1] Pieringer $\mathrm{H}$, et al. IgG4- related disease: an orphan disease with many faces. Orphanet journal of rare diseases. 2014:9:110.

[2] Haitao Du YW et al. IgG4-related disease and the curreny status of diagnostic approaches. EXCLI. 2012;11:651-8.

[3] Umehara $\mathrm{H}$, et al. Comprehensive diagnostic criteria for lgG4-related disease (lgG4-RD), 2011. Modern Rheumatology. 2012;22(1):21-30.

Disclosure of Interest: None declared

DOI: 10.1136/annrheumdis-2017-eular.2145

\section{FRI0600 THE EFFICACY OF DIFFERENT COLCHICINE DOSES IN TREATMENT OF FAMILIAL MEDITERRANEAN FEVER PATIENTS}

E. Uguztemur, S. Çelik, S. Sadri, E. Aşçı, G. Ergun, Ö. Velipaşalar, S. Yılmaz-Öner, C. Bes, N. Alpay-Kanıtez. Bakırköy Dr.Sadi Konuk Research and Training Hospital, Istanbul, Turkey

Background: Recommended colchicine dose in familial mediterranean fever (FMF) is $1-1.5 \mathrm{mg} /$ day in adults. If necessary it can be increased up to $3 \mathrm{mg} /$ day by clinical monitoring. In the final FMF recommendation report of the EULAR, it was reported that after 5 years of stable disease, in appropriate patients, the dose of colchicine may be reduced by close follow-up. However, the number of clinical trials supporting this recommendation is not enough.

Objectives: In this study, demographic and clinical characteristics of FMF patients whose disease under control and treated with different doses of colchicine were compared.

Methods: Among the all FMF patients attending to the rheumatology outpatient clinic between April and September 2016, only the patients in non-attacks period at least for the last 1 month were included to the study. Clinical and laboratory findings, MEFV gene mutations, drug compliance of the patients and duration and doses of the colchicine treatment were recorded. The 'international severity scoring system for familial mediterranean fever' (ISSF) score was calculated to determine disease severity. The patients who were under the control (less than 4 attacks per year and ISSF score $\leq 2$ ) divided to three gruops. These gruops were the patients taking low dose (average daily dose of colchicin $<1 \mathrm{mg}$ ), median dose $>1 \mathrm{mg} /$ day and $<1.5 \mathrm{mg} /$ day and standard dose $\geq 1.5 \mathrm{mg} /$ colchicine treatment at least for 3 years. Patients treated with DMARDs or biological therapy were excluded from the study.

Results: Of the 162 FMF patients enrolled into the ongoing cohort, 86 patients were excluded from the study due to 57 patients had active disease, 19 had not yet completed 3 years of colchicine treatment and 10 patients received biological or DMARD treatment. The remaining 76 patients (25 male, 51 female) met the study criteria. The mean age was $32 \pm 11.5$ years and the disease duration was $18.2 \pm 10.9$ years. Amyloidosis or organ failure was not detected in any of these patients. Because of various reasons (drug side effect, treatment incompatibility, physician advice), 16 patients (21\%) were treated with low dose colchicine (group A), 30 patients (39\%) with moderate dose of colchicine (group B) and the remaining 30 patients (39\%) with standard dose colchicine (group C). There were no statistically significant differences in demographic, clinical or laboratory data among these 3 subgroups.
Conclusions: Disease control in FMF is important to prevent amyloidosis and improve the quality of life. Recent studies contribute to the determination of treatment goals. Reducing the colchicine dose may increase drug compliance in this lifelong treatment. In our study, there was no difference between the treatment groups in amyloidosis, MEFV gene mutation or subclinical inflammation. These findings suggest that the dose of colchicine maybe reduced in inactive patients who determineted by the number of annual episodes and the ISSF score.

Disclosure of Interest: None declared

DOI: 10.1136/annrheumdis-2017-eular.6885

\section{FRI0601 HYPERFERRITINEMIC SYNDROME IN A GENERAL UNIVERSITARY HOSPITAL}

F. Pierini, I.J. Gandino, J.M. Martinez Perez, S. Ruta, M. Scolnik, E.R. Soriano. Rheumatology Section, Medical Services, Hospital Italiano de Buenos Aires, Buenos Aires, Argentina

Background: Hyperferritinemia is associated with severe inflammatory conditions, such as rheumatic diseases with systemic inflammatory responses, and multiorgan dysfunction syndromes.

Objectives: To determine which diseases are associated with hyperferritinemia in a tertiary hospital; to compare ferritin levels between these different entities and to evaluate relationship between levels of ferritin and mortality in these patients.

Methods: A retrospective study was carried out in which all patients over 18 years with at least one determination of serum ferritin equal to or greater than 1000 $\mathrm{ng} / \mathrm{ml}$ were identified in the laboratory database of our hospital between 1/1/2006 and 6/30/2016. Corresponding electronic medical records were reviewed and demographic data and clinical data were collected. Mortality was assessed at the end of follow-up. Descriptive statistical analysis and logistic regression analysis were performed in order to identify variables associated with mortality.

Results: A total of 1979 patients were included, 1235 men (62.4\%) with a mean age of 63.2 years (SD 17.2). Only 36 patients (1.8\%) presented a rheumatologic diagnosis as the only cause of high levels of ferritin, with Still's disease $(n=8)$ and systemic Vasculitis $(n=9)$ being the main diagnoses. Table 1 shows patients' characteristics grouped according to whether the elevation of ferritin was associated with a rheumatic disease or not. Median serum ferritin and transferrin saturation in both groups were similar (see Table 1). Mortality was lower for rheumatologic causes $(5.9 \%$ vs $37.2 \%, p<0.001)$. Variables that were associated with mortality in multivariable logistic regression analysis were: maximum ferritin value (OR 1,0004, 95\% Cl 1,0003-1,0004, $\mathrm{p}<0.001$ ) and age (OR $1.03,95 \% \mathrm{Cl} 1.02-1.04, \mathrm{p}<0.001$ ), whereas the diagnosis of a rheumatic disease was a protective factor (OR $0.11,95 \% \mathrm{Cl} 0.03-0.47, \mathrm{p}=0.003$ ). ROC curve for ferritin and mortality showed an area under the curve of $0.59(95 \% \mathrm{Cl}$ $0.58-0.62$ ). Ferritin levels greater than $3000 \mathrm{ng} / \mathrm{ml}$ showed a specificity of $89.2 \%$ and a sensitivity of $19.7 \%$ for mortality, regardless of cause of ferritin elevation.

\begin{tabular}{|c|c|c|c|c|c|}
\hline & $\begin{array}{c}\text { Rheumatic } \\
\text { disease } \\
(\mathrm{n}=35)\end{array}$ & & $\begin{array}{l}\text { Other causes of } \\
\text { ferritin elevation } \\
\qquad(n=1944)\end{array}$ & & $\mathrm{p}$ \\
\hline Female, $\mathrm{n}(\%)$ & $13(37.1)$ & & $731(37.6)$ & & 0.96 \\
\hline Mean age, years (DS) & $62.5(17.1)$ & & $52.4(21.1)$ & & $<0.001$ \\
\hline \multirow[t]{10}{*}{ Diagnostic } & Vasculitis & 9 & Solid cancer & 497 & \\
\hline & Still's disease & 8 & Infections & 336 & \\
\hline & $\begin{array}{l}\text { Rheumatoid } \\
\text { arthritis }\end{array}$ & 4 & $\begin{array}{c}\text { Onco-hematologic } 3 \\
\text { disease }\end{array}$ & 302 & \\
\hline & SLE & 3 & $\begin{array}{l}\text { Chronic renal } \\
\text { insufficiency }\end{array}$ & 236 & \\
\hline & $\begin{array}{l}\text { Seronegative arthritis } \\
\text { and psoriatic arthritis }\end{array}$ & $\begin{array}{l}3 \\
3\end{array}$ & $\begin{array}{l}\text { Hepatic } \\
\text { disease }\end{array}$ & 188 & \\
\hline & Others & 3 & Others & 152 & \\
\hline & Gout & 2 & $\begin{array}{l}\text { Hematologic } \\
\text { disease }\end{array}$ & 128 & \\
\hline & $\begin{array}{c}\text { Juvenile idiopathic } \\
\text { arthritis }\end{array}$ & 1 & Cardiovascular & 57 & \\
\hline & Myositis & 1 & Sepsis & 46 & \\
\hline & $\lg G 4$ & 1 & Iron overload & 2 & \\
\hline Serum ferritin, median (IQR) & $1622(1264-3639)$ & & $1460(1200-2140)$ & & 0.07 \\
\hline Tranferrin saturation, \%, median (IQR) & $38(19-50)$ & & $33(18-55)$ & & 0.83 \\
\hline Follow-up time, years, median (IQR) & $5.2(1,2-10.2)$ & & $5.7(1.2-8.9)$ & & 0.97 \\
\hline Mortality, n (\%) & $2(5.9)$ & & $698(37.2)$ & & $<0.001$ \\
\hline
\end{tabular}

Conclusions: Rheumatic diseases, represents a very small percentage of the causes of elevation of ferritin above $1000 \mathrm{ng} / \mathrm{ml}$, and were associated with lower mortality than the non-rheumatic causes. Serum ferritin levels were significantly associated with increased mortality regardless of the underlying cause.

Disclosure of Interest: None declared

DOI: 10.1136/annrheumdis-2017-eular.2460

\section{FRI0602 NATIONAL RECOMMENDATIONS ON THE USE OF IMMUNOMODULATORY DRUGS IN PATIENTS WITH NON-INFECTIOUS NON-MALIGNANT ANTERIOR UVEITIS}

G. Espinosa ${ }^{1}$, S. Muñoz-Fernandez ${ }^{2}$, J.M. García Ruiz de Morales $^{3}$, 